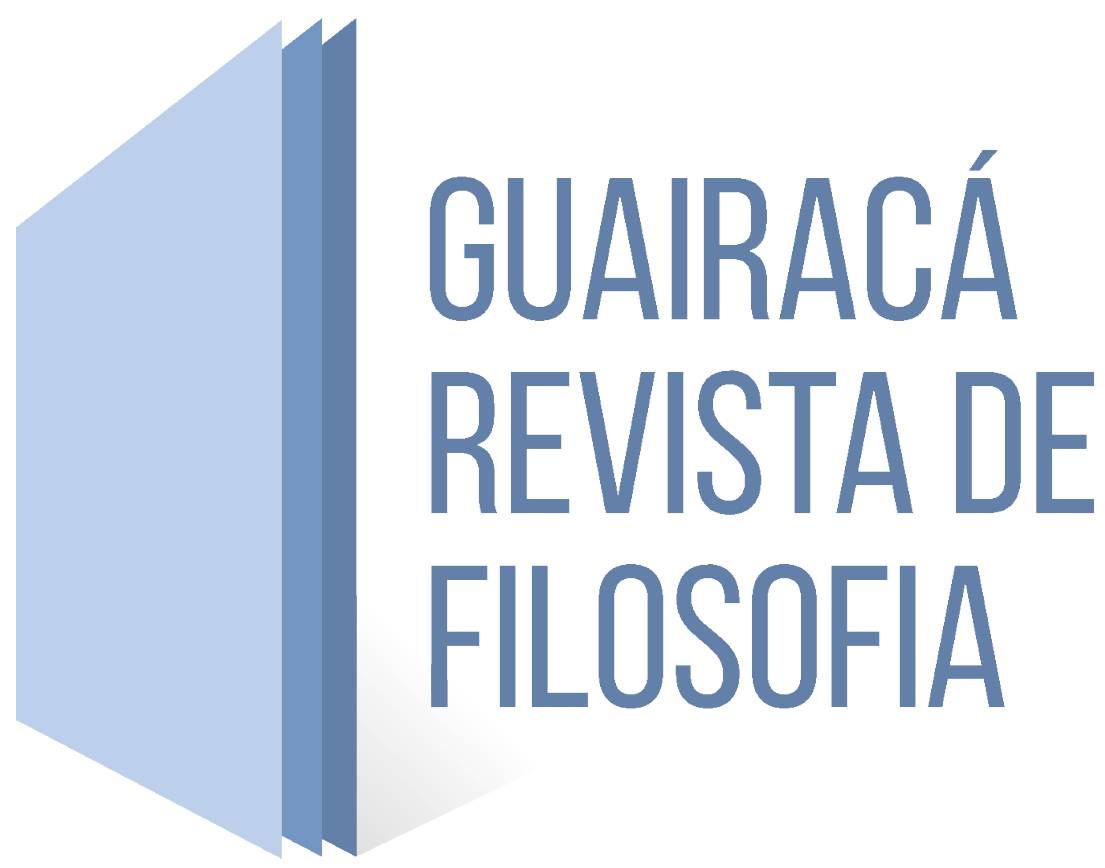

\title{
MELHORAMENTO MORAL: UM AVANÇO OU UM RETROCESSO?
}

Resumo: Dentre as diversas possibilidades de melhoramento humano perseguidas pelas tecnologias emergentes (Nanociência, Biotecnologia, Tecnologia da Informação e Ciências Cognitivas - NBIC) a que acena para o melhoramento moral do homem tem causado debates calorosos em seguimentos diversos. O cenário é tentador: poder elevar os níveis de empatia emocional, justiça, filantropia e, por que não dizer, de humanidade, através das NBIC é magnífico, poderia ser a "salvação da raça humana". De outra sorte, qualquer descuido nas etapas de viabilização poderia significar uma nova ordem de opressores, uma nova ordem de oprimidos, o que representaria um retrocesso moral. Frente ao exposto, pretende o presente artigo parametrizar (momentaneamente) os conceitos de melhoramento humano e de melhoramento moral, e extrair das correntes transumanista e bioconservadora ambas em suas versões mais duras - argumentos relativos à maneira pela qual as NBIC que objetiva o melhoramento moral deva (ou não) ser ministrada à sociedade e perguntar se, de fato, seriam elas por nós desejadas.

Palavras-chave: Melhoramento humano. Melhoramento moral. Filosofia moral.

1. Doutoranda em Filosofia na UNISINOS. E-mail: marcellepuc@yahoo.com.br 


\title{
MORAL ENHANCEMENT: AN ADVANCE OR A RETROGRESS?
}

\begin{abstract}
Among the various possibilities of human improvement pursued by emerging technologies (Nanoscience, Biotechnology, Information Technology and Cognitive Sciences - NBIC), which beckons for the moral enhancement of man has caused heated debates in diverse follow-ups. The scenario is tempting: being able to raise the levels of emotional empathy, justice, philanthropy and, why not say, humanity through NBIC is magnificent, could be the "salvation of the human race." Otherwise, any oversight in the stages of viability could mean a new order of oppressors, a new order of the oppressed, which would represent a moral setback. In view of the above, this article intends to (momentarily) parameterize the concepts of human enhancement and moral enhancement, and extract from the transhumanist and bioconservative currents - both in their hardest versions - arguments related to the way in which the NBIC that aims at moral improvement (or not) to be ministered to society and ask whether, in fact, they would be desired by us.
\end{abstract}

Keywords: Human enhancement. Moral enhancement. Moral philosophy.

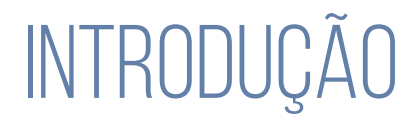

Elegemos, neste artigo, como a mais interessante narrativa mitológica que tangencia o tema: a utilização da tecnologia com o escopo de imprimir maiores aptidões ao ser humano [hábil para uma vida independente e autônoma, ou seja, saudável $^{2}$ ], a descrição do trabalho de Dédalo, pai de Ícaro, quando da construção das asas - protéticas - que permitiram que eles voassem e escapassem do labirinto no qual se encontrava o Minotauro (HAMILTON, 1983, p.199-200), acreditando ser essa uma das expressões mais remotas do anseio do homem por romper os seus entraves naturais, determinados pela natureza de sua espécie, bem como a primeira tentativa (ainda que mítica) de melhoramento humano realizado por meio de uma intervenção tecnológica.

Ao longo da narrativa histórica do humanidade, inúmeros exemplos poderiam ser coletados com o objetivo de ilustrar que o homem, per se, jamais se conformou com as adstrições que lhe foram impingidas por fatores deterministas,

2. Apesar de a teoria de Christopher Boorse relativa à construção do conceito de saúde ser muito combatida (ver AZEVEDO, M. A. Health as a clinic-epidemiological concept. Journal of Evaluation in Clinical Practice, v. 21, n. 3, p. 365-373, 2015), por hora trabalha-se com seu conceito de saúde, ou seja: saúde como ausência de doença. 
conjuntura da qual, em um primeiro momento, emergem os mitos. É o desejo do ilimitado, da perfeição e plenitude, que na origem de todos mitos se encontra em algum grau a representação de deuses (e outros seres) possuidores de atributos compensatórios das características circunscritas, das habilidades restritas e das capacidades limitadas dos seres humanos, mas hodiernamente, quando alguns ameaçados propalam os perigos de a Ciência no futuro conseguir romper as limitações, restrições e circunscrições das capacidades humanas, e outros maravilhados proclamam suas boas novas, estão a falar exatamente sobre o quê?

\section{A PARAMETRIZAÇÃO DO CONCEITO DE MELHORAMENTO HUMANO E DO MELHORAMENTO MORAL DERIVADO}

"Melhoramento humano" é o termo contemporâneo utilizado para designar as intervenções das tecnologias emergentes (Nanociência, Biotecnologia, Tecnologia da Informação e Ciências Cognitivas - NBIC) que possam potencializar o desempenho funcional das capacidades e habilidades humanas, porém corrente em filosofia é a não unificação conceitual e, habitualmente, filósofos propõem novos conceitos, conceitos próprios, não importando se o estabelecimento conceitual anterior data de séculos ou semanas. Ao se tratar do conceito de melhoramento humano não ocorre de forma diversa, são inúmeras as propostas, forma em que, optou-se aqui por apresentar um conceito inicial, para que haja uma mitigação das dúvidas relacionadas ao que será neste artigo tratado, que partiu da extração de parte do proposto Nick Bostrom e Rebecca Roache ${ }^{3}$.

Assim, melhoramento humano deve aqui ser compreendido - inicialmente - como o resultado da intervenção no ser humano saudável, hábil para a vida, de forma independente e autônoma, realizada através da nanociência, da biotecnologia, da tecnologia da informação e das ciências cognitivas, com o intuito exclusivo de lapidar o desenvolvimento ou a performance de suas habilidades e capacidades ${ }^{4}$.

3. [...] "tipicamente contraposto à terapia. Em termos gerais, a terapia visa consertar algo que deu errado, curando doenças específicas ou lesões, enquanto as intervenções de melhoria visam melhorar o estado de um organismo além do seu estado saudável normal." (BOSTROM; ROACHE, 2007, p. 120) (T.A.)

4. Em um sentido similar: “Tecnologias biomédicas, como fármacos e técnicas cirúrgicas, são usadas cada vez mais não apenas para combater doenças, mas também para aumentar as capacidades de indivíduos normais e saudáveis, uma prática comumente referida como biomelhoramento humano." (T.A.). THE OXFORD UEHIRO CENTER FOR PRACTICAL ETHICS. Enhancement. Disponível em: https://www.practicalethics. ox.ac.uk/enhancement, acessado em 11/11/2018. 
Tais intervenções, que objetivam o melhoramento humano, podem ser empregadas em áreas específicas, como, por exemplo, as que visam o prolongamento da vida, o melhoramento das capacidades físicas, o melhoramento do humor e/ou da personalidade, o melhoramento do aprendizado, da memória, da concentração, e as intervenções pré e perinatal que objetivam o nascimento de um ser humano modificado. Algumas dessas áreas já esboçam suas feições em nossa sociedade, como é o caso dos ciborgues ${ }^{5}$, da seleção genética ${ }^{6}$, da droga que proporciona "alegria constante" $^{\prime 7}$, dos implantes de chips nos braços e nas mãos para abrir portas e fazer conexões com tablets etc., mesmo que ainda longe do que possa ter sido projetado pelos cientistas tais exemplos já nos permitem vislumbrar o que as tecnologias emergentes terão para nos oferecer em um futuro não muito distante.

Uma das mais recentes áreas de pesquisa vinculada ao melhoramento humano é a do melhoramento moral, que insurge da conclusão sobre a ineficácia das fórmulas tradicionais que usamos até hoje para decidir "como devemos viver e porquê" ${ }^{\prime \prime}$.

Séculos de reflexão sobre a moralidade do homem, sobre quais são os critérios que o leva a decidir sobre quais são as ações certas, elogiáveis e sobre quais são as ações erradas, censuráveis, sobre se o que motiva suas ações morais seria de expressão utilitarista, seria de expressão virtuosa, de expressão de princípios, ou de "razão essencial", ou se suas razões são de ordem externa ou interna, denotam que o homem pensa a moralidade como ainda portadora de uma atrofia, e que continua gestando o temor da destruição do homem pelo homem. As aspirações das conhecidas teorias morais, que, isoladas, não foram capazes de ceifar da terra as ações humanas julgadas erradas, passíveis de reprovação e censura, hodiernamente, para os filósofos transumanistas são avigoradas com positivas expectativas relativas ao melhoramento moral, o que poderia "evitar" uma catástrofe; de forma diversa, os filósofos bioconservadores enxergam nessa mesma possibilidade um acontecimento calamitoso, como mais à frente se verá. Mas o que seria exatamente o melhoramento moral?

Encontra-se a tentativa de uma resposta a essa pergunta na expressiva maioria dos textos que trata sobre o assunto, sem que se possa, ao final, dar como finda a questão. Porém, o que se tem de concreto é a ideia de que o homem faz menos

5. Manfred E. Clynes e Nathan S. Kline em 1960 criam o termo 'ciborgue' para se referir a um ser humano melhorado que poderia sobreviver no espaço sideral. Disponível em: https://pt.wikipedia. org/wiki/Ciborgue, acessado em 15/01/2019.

6. Normas Técnicas para a Utilização das Técnicas de Reprodução Assistida do Conselho Federal de Medicina - Brasil.

7. Fluoxetina: inibidor seletivo da recaptura da serotonina.

8. Referência às palavras de James Rachels ao indicar a simplicidade e completude das palavras de Sócrates sobre a moralidade (RACHELS, 2006, p. 1). 
o que moralmente deveria fazer mais e não consegue evitar, mesmo consciente do mal, a prática de ações censuráveis (McNAUGHTON, 2017, p. 1).

Destarte, melhorar o senso de justiça ou melhorar a capacidade empática ou melhorar a motivação ${ }^{9}$ para a boa ação (DOUGLAS, 2008, p. 13) ou o senso de altruísmo ou a diminuição do egoísmo, o desenvolvimento da razão para as melhores escolhas ou ainda, melhorar um determinado conjunto que envolve a soma de princípios, motivações e as ações em si (NAHRA; OLIVEIRA, 2012, p. 57) ou, quem sabe, o desenvolvimento de "moralidade essencial"10, nos moldes de Engelhardt, são possibilidades que, ao menos em teoria, poderiam ser alvo de tecnologias emergentes com o escopo de promover o melhoramento moral, uma vez que se considera, neste texto, que melhoramento moral é vertente do melhoramento humano que tem por finalidade viabilizar a prática de ações elogiáveis, bem como - e talvez principalmente - a não prática de ações censuráveis, cometidas e baseadas em crenças fundamentadas em argumentum ad baculum ou ad ignoranciam, v.g.: casamentos forçados ${ }^{11} \mathrm{e}$ atos posteriormente desmentidos pela Ciência, mas que suas negações até então era tidas como heréticas, como "um texto na Bíblia considerado verídico, [...] as lebres ruminam.” (RUSSELL, 2009, p. 3).

À vista disso, vamos admitir que uma NBIC que produza melhoramento moral esteja pronta para ser utilizada, imaginariamente o Serpram Fluox Moral-Up, que tornará seus consumidores em "seres hiperaltruístas". Surge nesse ponto uma série de questionamentos que não têm e certamente não terão respostas pacíficas pelas próximas décadas. Dentre elas: (i) de que maneira tal NBIC será disponibilizada e, de importância expoente, (ii) de que forma tal NBIC será ministrada, ou melhor, o melhoramento moral, agora [tecnologicamente] disponível, deve ou não ser administrado de maneira compulsória; e (iii) o que realmente desejamos com o melhoramento moral?

Com a intenção de incentivar o debate sobre quais poderiam ser tais respostas, traz-se um exemplo para ser discutido, observando que não serão considerados - neste momento - indivíduos com déficits patológicos que resultam em diminuição ou ausência de empatia, de razão, de altruísmo, de bons motivos etc., e sim os que praticam algumas ações elogiáveis, mas também outras censuráveis,

9. Definição de motivo dada por Thomas Douglas: "estados ou processos psicológicos -mentais ou neurais - que irão, dada a ausência de motivos opostos, fazer com que a pessoa aja."

10. Sobre moralidade essencial ver AZEVEDO, M. Fundamentos da Bioética, 2013, p.31-33.

11. “Crime de honra é a expressão que designa os actos de extrema violência, geralmente homicídio, perpetrados por membros de uma família contra uma mulher do mesmo núcleo (irmã, filha, esposa, ...) pelo facto de considerarem a sua conduta imoral e nociva para a honra familiar. Os motivos pelos quais este crime é observável hodiernamente são diversos: recusa da mulher em aceitar um casamento imposto pela família; ineficiência na esfera doméstica; pretensão de divórcio; adultério ou o facto de ter sido vítima de violência sexual. Cada um destes factores é considerado um atentado à honra familiar e o modo privilegiado de restabelecê-la é eliminar o membro que a denegriu." Disponível em: http://feministactual.blogspot.com/2006/06/crime-de-honra.html, acessado em 14/01/2019. 
que poderiam ter sido de alguma maneira evitadas, e que não são reconhecidos pela sociedade como propriamente "indivíduos imorais", mesmo que eles não estejam no - nível ideal da moral pretendida -, melhor dizendo, mesmo que eles possam praticar mais ações elogiáveis. Isso porque admitir quaisquer déficits neste momento nos expulsaria dos limites da conceituação de melhoramento moral anteriormente proposta. Assim, o indivíduo deve possuir algum grau de moralidade humana [admitindo que tal composição se dá por um ou mais dos elementos que foram expostos], ao ponto de poder ser estimado como "homem moral"; um homem que age, ainda que minimamente, conforme o esperado, dentro das regras morais da sua sociedade, uma sociedade contemporaneamente democrática. Assim sendo, o que poderia levá-lo, espontaneamente, a entrar em uma farmácia, comprar o Serpram Fluox Moral-Up e consumi-lo?

Passemos então ao "nosso homem moral", doravante " $\mathrm{M}$ ", que, após refletir sobre suas ações, entendeu que poderia "se melhorar moralmente", uma vez que se ressentia muito em se preocupar em proporcionar mais à sua filha do que as criancinhas miseráveis da África. Para sua filha, ele destinava trinta por cento do seu orçamento, enquanto que meio por cento de seu orçamento era destinado às crianças em estado de miséria. Sua vontade era equalizar a distribuição de sua renda, mas, embora tenha feito esforços hercúleos, sempre acabava aceitando o padrão de sua sociedade "primeiro, aos meus; depois, aos alheios"12, pois "retirar" recursos de sua própria filha para ajudar uma pessoa que ele sequer conhecia também não lhe parecia uma ação elogiável ${ }^{13}$, até o momento em que M se depara com um anúncio do Serpram Fluox Moral-Up e descobre a "moral em cápsulas", um fármaco, de última geração, que ingerido uma vez ao dia, além de acelerar sua produção de oxitocina, dopamina e serotonina, ainda inibiria a recaptação das substâncias produzidas, o que consequentemente tornaria seu comportamento moral, social, empático, altruísta etc. elevado ao máximo. Ele então se tornaria "mais, mais muito mais moral". Além do que, qualquer traço egoísta, qualquer traço agressivo, mesmo que nos seus aspectos competitivos ${ }^{14}$, ainda que protetivos, seriam de plano aniquilados.

Um indivíduo nessas condições - moralmente já considerado saudável -, no cenário mundial atual, realmente pleitearia o acesso a tais mudanças? E esse

\section{Provérbio popular.}

13. Talvez se hoje se fossemos perquirir como a nossa sociedade julgaria a ação de um pai que deixou de proporcionar educação, saúde e laser - de excelência - ao seu filho para mandar tais recursos excedentes para a África a maioria diria ser uma ação elogiável, mas na prática é custoso acreditar que essas mesmas pessoas deixassem, de fato, de colocar seus filhos nas melhores escolas privadas, de fornecê-los um bom plano de saúde privado e de mandá-los para a Disney duas vezes por ano, para fazer mais doações.

14. TRIVERS (1971). Resumo. "Indivíduo humano visto como possuidor de tendências altruístas e para trapaças, cujas expressões são sensíveis às variáveis de desenvolvimento que foram selecionadas para estabelecer as tendências em um equilíbrio apropriado ao ambiente social e ecológico local.". 
indivíduo modificado moralmente, agora pertencente à categoria de pós-humanos, com sua capacidademoralem um nível dealtruísmo expoente, visto até então somente na categoria dos santos, seria tratado de que forma pelos outros membros da sua sociedade? Ou não se coloca esse problema frente à argumentação de que "sempre podemos nos melhorar [moralmente] e que isso seria irrefutavelmente sempre para o Bem, não somente para o bem do indivíduo melhorado mas, e principalmente, para o bem da sociedade, quiçá da humanidade"? Dentre as inúmeras críticas que se poderia fazer sobre essa colocação temos a constante ligação da moral a um dos tipos de utilitarismo, mas pensar moral, melhoramento moral, sem pensar nas consequências das ações do indivíduo sem considerar as consequências dessas mesmas ações para seu grupamento social não parece fazer sentido. Não se pode falar da moralidade de um único indivíduo, fora de um contexto social.

Pensar os aspectos práticos do melhoramento moral entendido da forma anteriormente proposta coloca-nos frente a outro questionamento, a saber: o que desejamos com o melhoramento moral?

\section{VERTENTES TRANSUMANISTAEBIOCONSERVADORA}

Anteriormentefoi salientado que são várias asáreas em que o melhoramento humano está sendo desenvolvido, dentre elas a área do melhoramento moral, e que transumanistas e bioconservadores divergem não somente quanto à conceituação, mas, principalmente, quanto às suas possíveis aplicações. Para que possam ser perquiridos os pontos pretendidos neste artigo, passemos ao excerto do texto de um dos mais importantes representantes da corrente transumanista, Nick Bostrom $^{15}$, no qual ele nos oferta a explicação, digamos, formal sobre exatamente no que consiste tal teoria:

\footnotetext{
O transumanismo é uma maneira de pensar sobre o futuro que se baseia na premissa de que a espécie humana, em sua forma atual, não representa o fim de nosso desenvolvimento, mas sim uma fase comparativamente precoce. Nós formalmente definimos da seguinte forma:

(1) O movimento intelectual e cultural que afirma a possibilidade e conveniência de melhorar fundamentalmente a condição humana através da razão aplicada, especialmente desenvolvendo e disponibilizando tecnologias amplamente disponíveis para eliminar o envelhecimento e aumentar consideravelmente as capacidades intelectuais, físicas e psicológicas humanas.

(2) O estudo das ramificações, promessas e perigos potenciais de tecnologias que nos permitirão superar as limitações humanas fundamentais e o estudo relacionado das questões éticas envolvidas no desenvolvimento e uso de tais tecnologias (BOSTROM, 2003).
}

15. Ao lado de outros expoentes como Kurzweil, Persson, Grossman, Sharman, Cunninghan, e Savulescu, para citar apenas alguns. 
Logo, o entendimento de transumanistas como Nick Bostrom consiste na defesa do amplo desenvolvimento de todo equalquer tipo demelhoramento humano, bem como na defesa da ampla liberdade dos indivíduos quanto à utilização das tecnologias melhoristas e quanto ao domínio do poder de decisão sobre sua própria evolução, anteparando que os seres humanos não possuem nenhuma característica que os tornem especiais, impassíveis de modificações ${ }^{16}$.

Ocorre que o transumanismo defende, ao mesmo tempo, que cada uma das modalidades de melhoramento deve ser analisada isoladamente e não dentro de um único bojo. Isso significa que o melhoramento moral não deve ser objetado sob a égide da generalidade. Encontramos então uma curiosa alusão, aparentemente contraditória, feita por Ingmar Persson e Julian Savulescu, considerados transumanistas: o melhoramento humano, na modalidade melhoramento moral deve ser revestido pelo caráter da obrigatoriedade, sob pena de as outras formas de melhoramento implementadas coagirem o afloramento de amores próprios, em detrimento alheio, ou seja, de egoísmo, o que levará a humanidade ao seu fim [posição que sofreu e sofre saraivadas de críticas, dentre elas a de não ter como se fazer tal afirmação; não há elementos que possam garantir que o não melhoramento moral como antecedente poderá levar o ser humano a ruína], (PERSSON; SAVULESCU, 2008, p. 7-11).

Na outra margem do debate surge, como opositor à tese transumanista, o retrocitado Bioconservadorismo, cujo representante aqui selecionado é Michael Sandel17, que prega "que tecnologias de melhoramento humano poderiam ser 'desumanizantes'", e por isso "minar a nossa dignidade humana ou inadvertidamente erodir algo que é profundamente valioso a respeito de ser humano, mas que é difícil de ser colocado em palavras ou de se levar em conta em uma análise de custo e benefício."18

Frente ao exposto, admitamos, num primeiro momento, como pregam os bioconservadores, que o melhoramento moral - que se vale de biotecnologias - deva ser rechaçado por colocar em risco aspectos fundamentais da constituição do ser humano (o que lhe confere um status [humano] diferenciado) e por amortecer uma de suas principais características, a saber: a liberdade (SANDEL, 2007), e que (i) não há limites para que o indivíduo se refine moralmente, pois sempre poderemos ser mais ajustados no que diz respeito à moral utilizando as vias convencionais como educação, cultivo de bons hábitos, cultura, conhecimento etc. Logo, ao assumir a tese bioconservadora, estaremos admitindo - necessariamente - que jamais seremos

16. BOSTROM, N.; SAVULESCU, J. Human Enhancement Ethics: The State of the Debate. Disponível em: https://nickbostrom.com/ethics/human-enhancement-ethics.pdf, acessado em 14/01/2019.

17. Nomes como os de Leon Kass, Francis Fukuyama, George Annas, Wesley Smith e Jeremy Rifkin, por exemplo, são também referências importantes dentro do Bioconservadorismo.

18. BOSTROM, N. In Defense of Posthuman Dignity. Bioethics, v. 19, n. 3, p. 202-214, 2005. Disponível em: https://nickbostrom.com/ethics/dignity.html, acessado em 20/05/2019. 
moralmente suficientes pelas vias tradicionais, melhor dizendo: tão bons quanto poderíamos ser, porque sempre vamos pode ser melhores [soaria essa afirmação como um argumento falacioso?] e que o melhoramento moral biotecnológico nos faria perder nossas características "mais" humanas. O resultado seria então a desastrosa submissão dos humanos aos transumanos, a nova raça dos melhorados [morais]; ou (ii) a disponibilização de uma NBIC de melhoramento moral não seria uma excludente dos métodos tradicionais, mas sim um adjuvante que nos colocaria em um patamar de moralidade no qual não houvesse mais a possibilidade de melhoramento ${ }^{19}$ ?

Ao decidirmos pela primeira opção (i), concluiremos que somente o melhoramento moral biotecnológico nos permitiria uma excelência moral. Contudo, essa "excelência moral" hipoteticamente pode não ser imprescindível para o maior bem do indivíduo, nem para o maior bem da sociedade, se a olharmos, por exemplo, sob a perspectiva da teoria da Utilidade Marginal Decrescente ${ }^{20}$, a ver:

1. a utilidade marginal é a satisfação que um indivíduo recebe pelo consumo de uma unidade adicional de um bem;

2. quanto mais unidades desse bem possuir o indivíduo, mais saciado ele estará e menos importância será atribuída ao bem;

3. logo, o nível de satisfação tende a diminuir a cada unidade do bem acrescentada.

Ad argumentandum, para questionar se, como acima aludido, a "excelência moral" pode hipoteticamente não ser imprescindível para o maior bem do indivíduo, nem para o maior bem da sociedade, transportemos a teoria econômica para o domínio da teoria moral:

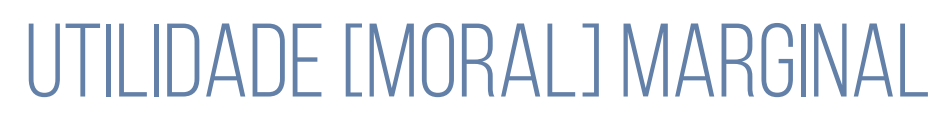

1. A utilidade [moral] marginal é a refinação moral atribuída ao indivíduo (e/ou sociedade-efetividade) por cada grau de moralidade que lhe for

19. "Há muitas razões para acreditar que tal "garantia de segurança", teoricamente oriundas do melhoramento moral, são impossíveis, porque as falhas em qualquer intervenção humana não é apenas possível, mas são sem dúvida inevitável. Não existe tal coisa como "garantia de segurança." (HARRIS, 2011, p. 20) (T. A.)

20. “O argumento utilitarista para a redistribuição de renda se baseia na hipótese da utilidade marginal decrescente. Parece razoável que um dólar a mais de renda para uma pessoa pobre the proporcione mais utilidade adicional do que um dólar a mais de renda para uma pessoa rica. Em outras palavras, à medida que a renda de uma pessoa aumenta, o bem-estar adicional derivado de um dólar adicional de renda diminui. Essa suposição bastante plausível, junto com o objetivo utilitarista de maximização da utilidade total, implica que o governo deveria tentar atingir uma distribuição de renda mais igualitária." Disponível em: http://proeconomia.webnode.com/news/a3-utilitarismo-valorutilidade-principio-da-utilidade-marginal-decrescente/, acessado em 05/08/2017. 
acrescentado;

2. Quanto mais elevados os graus de moralidade, mais refinado moralmente o indivíduo estará e menos importância efetiva será a ela atribuída;

3. Logo, o nível de refinamento moral/efetividade tende a diminuir a cada grau de moralidade acrescentada.

A hipótese da Utilidade Moral Marginal nos serviria para que pudéssemos reconhecer o cenário moral atual com o propósito de melhor decidir o rumo desejável para o melhoramento moral, onde estamos moralmente, qual a necessidade de mais moral, para quem e de que forma. Acolher tal posição representaria acolher a existência de um "melhor Pareto moral" 21, revelador da compreensão do desejo moral [máximo] de uma sociedade. Não obstante não sabermos se existe ou não esse pareto moral, dito também "ótimo moral", vários posicionamentos doutrinários canalizam ideias análogas em suas teorias ${ }^{22}$. Salientamos que a existência de um "melhor Pareto moral" (vinculado à escolha social) poderia refletir, ou não, um grau expoente da moralidade do indivíduo, uma moralidade perfeita, ou uma excelência moral - vinculado à construção de virtudes, ou até mesmo ao cumprimento pela razão de regras morais com as quais um indivíduo não pactua. Esta é a primeira terminação.

De outra sorte, ao decidirmos pela opção seguinte, (ii) - melhoramento moral como adjuvante (mas que ainda assim permitiria o reconhecimento do melhor Pareto moral) -, o mais razoável seria decidir pela não eletividade de sua aplicação, caso em que - vis-à-vis o cenário social atual - os "melhorados moralmente" padeceriam de toda ordem de abusos por parte dos "não melhorados" ${ }^{23}$ (que, certamente, não é o que se deseja), como já mencionado.

\footnotetext{
21. Princípio de Pareto (se todo mundo na sociedade prefere um estado social do que outro, então a escolha daquele preferido deverá ser feita por ser o melhor para aquela sociedade como um todo); possui aspectos não liberais. A saída de Amartya Sem: a garantia última da liberdade individual resta não sobre regras de escolha social, e sim sobre o desenvolvimento de valores individuais que respeitem as escolhas pessoais de cada um (SEN, 1970, p. 155-156). A busca pelo bem-estar de todos em todas as situações seria incompatível com valores liberais, uma vez que a sociedade não poderia deixar um indivíduo livre para ler o que quisesse, dormir como quiser, se vestir como quiser, etc., independentemente das preferências dos outros na comunidade (SEN, 1970, p. 157). Mesmo que o critério de Pareto seja visto como expressão da liberdade individual, em situações de escolhas sociais que envolvam mais que duas alternativas, pode ter consequências profundamente não liberais (SEN, 1970, p. 157).

22. John Rawls, Amartya Sen, Igmar Persson e Julian Savulescu, dentre outros.

23. A propósito, "Haldane, em sua obra Daedalus, retrata uma imagem atraente do futuro que poderia sobrevir, se talvez as descobertas científicas fossem usadas para promover a felicidade humana. Por mais que eu queira concordar com tal previsão, minha longa experiência com estadistas e governos me deixou um pouco cético. Temo que a ciência seja usada para promover o poder dos grupos dominantes, em vez de buscar a felicidade e a prosperidade dos homens." (RUSSELL, 1924) (T.A.)
} 
Acredita-se que a proposta para que o melhoramento moral fosse na prática ${ }^{24}$ disponibilizado (no sistema público e privado ${ }^{25}$ ) sem o caráter compulsório ${ }^{26}$ (ataque mor ao direito à liberdade do homem) seria uma consideração razoável somente se frente ao resultado positivo de um cálculo que atentasse para as ações de todos os envolvidos naquela sociedade, nos moldes de uma teoria dos jogos; a teoria do altruísmo recíproco de Trivers seria um bom modelo para se trabalhar ${ }^{27}$.

Reflete-se também ser delicado trabalhar com "somentes". Julgar um ato censurável ou elogiável "somente" com base em suas consequências, ou "somente" com base na intenção do agente, ou "somente" com base nas virtudes do agente parecem critérios necessários para o estabelecimento "de um entendimento sistemático da natureza da moralidade e do que ela exige de nós" (RACHELS, 2006, p. 1), mas não suficientes. O processo de cognição moral permanece ad definiendum.

Díspar a hipótese em que o melhoramento moral é entendido pelos transumanistas, ou seja, de que não faz a menor diferença se sua aplicação será em indivíduos saudáveis ou se em portadores de patologias, ou com déficits de saúde em geral (BOSTROM, 2008). Melhoristas/transumanistas não prezam a distinção entre desenvolvimento biotecnológico para aplicação terapêutica e desenvolvimento biotecnológico para aplicação de melhoramento. Sob essa perspectiva, o melhoramento moral deveria permanecer - exclusivamente - de utilização eletiva? Em nenhuma conjectura caberia o pressuposto de uma "compulsoriedade" na utilização do melhoramento moral? Vejamos.

Considerando-se a vertente que não mais adota o melhoramento moral como as tecnologias emergentes direcionadas de forma restrita aos indivíduos moralmente saudáveis, mas também àqueles com déficits morais de qualquer natureza: neuroquímico, cultural, ambiental, psicológico (na versão mais dura que ainda

24. Data vênia as considerações de Trivers sobre a impossibilidade de "seguranças e garantias". Ver: TRIVERS (1971).

25. Garantia de acesso.

26. Ventilada por Persson e Savulescu em Unfit for the future, 2012.

27. The evolution of reciprocal altruism, Robert L. Trivers, 1971. Resumo: Um modelo é apresentado para explicar a seleção natural do que é denominado comportamento reciprocamente altruísta. $\mathrm{O}$ modelo mostra como a seleção pode operar contra o trapaceiro (não-reciproco) no sistema. São discutidos três exemplos de comportamento altruísta, cuja evolução o modelo pode explicar: (1) comportamento envolvido na limpeza de simbioses; (2) gritos de advertência em aves: e (3) altruísmo recíproco humano. Em relação ao altruísmo recíproco humano, mostra-se que os detalhes do sistema psicológico que regula esse altruísmo pode ser explicado pelo modelo. Especificamente, a amizade, a aversão, a agressão moral, a gratidão, a simpatia, a confiança, a suspeição, a confiabilidade, os aspectos da culpa e algumas formas de desonestidade e hipocrisia podem ser explicadas como importantes adaptações para regular o sistema altruísta. Cada indivíduo humano é visto como possuindo tendências altruístas e de trapaças, cuja expressão é sensível às variáveis de desenvolvimento que foram selecionadas para estabelecer as tendências em um equilíbrio apropriado ao ambiente social e ecológico local (T.A.). Disponível em: https:/greatergood.berkeley.edu/images/uploads/TriversEvolutionReciprocalAltruism.pdf, acessado em 14/01/2019. 
tende a rejeitar a participação neuroquímica), per se, ou em conjuntos diversificados, por que não se poderia pensar para esses casos, como dos homicidas compulsivos, estupradores compulsivos e toda sorte de facínoras que reiteradamente - em função de suas patologias - impingem danos profundos e irreversíveis à sociedade, a penalidade do melhoramento moral biotecnológico ${ }^{28}$ até o ponto em que as recidivas se tornassem próximas a zero? Nessa hipótese conseguimos entrever o argumento defendido em Moral Enhacement por Thomas Douglas (DOUGLAS, 2008) ganhar corpo, não há como se falar em nenhuma espécie de prejuízo, nenhum dano que pudesse ser causado pelo melhoramento moral ministrado aos que não possuem moral em nenhum grau. Teoricamente não haveria danos nem ao condenado, nem à sociedade, de outra sorte todos seriam beneficiados ${ }^{29}$ e soaria no mínimo falaciosa a argumentação da manutenção da "liberdade ad eternum" para causar danos. Lembrando que a possibilidade de o melhoramento moral compor o rol das penalidades de determinados crimes, surge também em versão "não compulsória", mas facultativa à pena de restrição de liberdade, na qual o condenado teria o direito de optar entre permanecer preso e ser melhorado moralmente ${ }^{30}$. Mas o que realmente desejamos?

\section{CONCLUSÃ̃O}

As tecnologias emergentes propulsoras do melhoramento humano, ainda que não tenham atingido seu ápice e ainda que não se saiba quando e como isso acontecerá, hodiernamente, já podem nos dar mostras das possíveis alterações, modificações e realinhamento dos componentes biológicos do ser humano responsáveis pelos humores, sentimentos e, porque não dizer, motivações morais. Isso significa em realidade que tanto o melhoramento moral pretendido pelos transumanistas, de aplicação facultativa ou compulsória, quanto sua negativa veemente por parte dos bioconservadores, demudaram o cenário das discussões sobre moralidade. Provavelmente as reflexões impelidas pelos avanços tecnológicos

28. A comparação a castração química não encontra sede na pergunta levantada, vez que a homossexualidade, mesmo que a prescrição tenha sido fundamentada em um argumento falacioso, não acredito que hoje alguém possa ter sinceras dúvidas quanto ao mal causado por um estuprador contumaz ou por assassino em série, a ponto de imaginar que se hodiernamente o erro da castração química aplicada aos homossexuais é considerada uma monstruosidade, existe então a possibilidade de, [no futuro do futuro] também nos arrependermos de ter tornado compulsório o melhoramento para doentes desse porte. Neste caso, vou usar uma frase de Elizabeth Anscombe "sinceramente, com esse tipo de pessoa faço questão de não discutir".

29. Observe-se que não estão nesse cálculo a diminuição dos gastos estatais na manutenção dos condenados, nem os custos com as políticas de reinserção social.

30. Versão apresentada por Cinara Nahra na Conferência Ética Aplicada e Políticas Públicas - UFSC, 2017. 
farão com que conceitos sejam reformulados não só quanto à moralidade, mas, e principalmente, acreditamos, que sejam reformulados conceitos relativos ao indivíduo e sua humanidade. Para além de uma superação moral, o melhoramento moral gestará a construção de novos paradigmas e não existem bons motivos para que se tema a biotecnologia, não vivemos no mundo das trevas, no qual curas abominavam os "revolucionários homens da ciência" (RUSSELL, 2009, p. 3).

Defendemos hoje o amplo diálogo sobre tais melhoramentos. Importante que se entenda antes de tudo o que desejamos com o desenvolvimento das biotecnologias. Queremos que o melhoramento seja desenvolvido e disponibilizado para todos? Queremos que, ao par da escolha facultativa, ele seja usado como um fármaco e/ou como penalidade para criminosos patologicamente contumazes? Essa são apenas algumas das inúmeras alternativas componentes de acaloradas discussões e que talvez, sem muito alarde, já venham operando reconfigurações sobre a moralidade. Inevitável, porém, que os novos entendimentos, que as novas conceituações e até mesmo a evidência de melhor Pareto moral se tornarão, pelo menos durante algum tempo, na história do homem um novo paradigma, uma vez que raramente a moral consegue se libertar do conservadorismo. Sobre quais as consequências da aplicação do melhoramento moral, estamos distantes da resposta tanto quanto de Ogle-TR-56b ${ }^{31}$. Não temos garantias ou seguranças se a ciência nos trará o céu ou o inferno, mas devemos nos preparar para as mudanças gigantescas que estão por vir. Que continuem os debates!

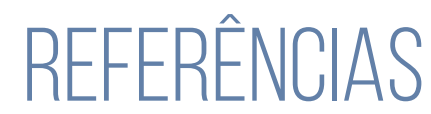

AZEVEDO, M. A. Health as a clinic-epidemiological concept. Journal of Evaluation in Clinical Practice, Oxford, UK, v. 21, n. 3, p. 365-373, 2015.

BOSTROM, N. In Defense of Posthuman Dignity. Bioethics, v. 19, n. 3, p. 202-214, 2005. Disponível em: https://nickbostrom.com/ethics/dignity.html, acessado em 20/05/2019.

BOSTROM, N. The Transhumanist FAQ, 2003. Disponível em: https://nickbostrom. com/views/transhumanist.pdf, acessado em 20/05/2019.

BOSTROM, N.; ROACHE, R. Ethical issues in human enhancement. In: RYBERG, J.; PETERSEN, T.; WOLF, C. New Waves in Applied Ethics. London, UK: Palgrave Macmillan, 2007. p. 120-152.

BOSTROM, N.; SAVULESCU, J. Human Enhancement Ethics: The State of the Debate

31. O PLANETA mais distante da Terra. BBC BRASIL.com., 08/01/2003. Disponível em: https://www. bbc.com/portuguese/ciencia/030108_planetaep.shtml, acessado em: 15/01/2019. 
Disponível em: https://nickbostrom.com/ethics/human-enhancement-ethics.pdf, acessado em 14/01/2019.

DOUGLAS, T. Moral Enhancement. Journal of Applied Philosophy, v. 25, n. 3, 2008.

Disponível em: https://onlinelibrary.wiley.com/doi/full/10.1111/j.14685930.2008.00412.x, acessado em 27/05/2019.

HAMILTON, E. A mitologia. Lisboa: Publicações Dom Quixote, 1983.

HARRIS, J. Moral enhancement and freedom. Bioethics, v. 25, n. 2, p. 102-111, fev. 2011.

MCNAUGHTON. D. Debilidade Moral. Crítica na Rede, 01/02/2017. Disponível em: https://criticanarede.com/fil_vontade.html, acessado em 15/01/2019.

NAHRA, C.; OLIVEIRA, A. C. de (Org.) Aperfeiçoamento Moral (moral enhancement). Natal: Programa de Pós-graduação em Filosofia da UFRN, 2012.

O PLANETA mais distante da Terra. BBC BRASIL.com., 08/01/2003. Disponível em: https://www.bbc.com/portuguese/ciencia/030108_planetaep.shtml, acessado em: 15/01/2019.

PERSSON, I; SAVULECU, J. The perils of cognitive enhancement and the urgent imperative to enhance the moral character of humanity. Journal of Applied Philosophy, Aberdeen, UK, v. 25, n. 3, p. 162-177, 2008.

RACHELS, J. Os elementos da filosofia moral. Tradução de Roberto Cavallari Filho. 4. ed. São Paulo: Manole, 2006.

RUSSELL, B. Religião e ciência. São Paulo: FUNPEC, 2009.

. Ícaro, o el futuro de la ciência. Disponível em: http://www.filosofos.net/russell/ obras/russell_obras_icaro.htm, acessado em 15/08/2017.

SANDEL, M. Contra a perfeição: ética na era da engenharia genética. São Paulo: Civilização Brasileira, 2007.

SEN, A. The Impossibility of a Paretian Liberal. Journal of Political Economy, v. 78, n. 1, p. 152-157, 1970.

THE OXFORD UEHIRO CENTER FOR PRACTICAL ETHICS. Enhancement. Disponível em: https://www.practicalethics.ox.ac.uk/enhancement, acessado em $11 / 11 / 2018$. 
TRIVERS, R. The evolution of reciprocal altruism. The Quarterly Review of Biology, Chicago, v. 46, n. 1, p. 35-57, 1971.

VALDENOR. Paradoxo da impossibilidade do ótimo de Pareto liberal: formulação por Amartya Sen, respostas de Gerald Gaus e James Buchanan. Tabula (não) Rasa $\mathcal{E}$ Libertarianismo Bleeding Heart: Naturalismo e darwinismo/Economia livre e justiça social, 14/09/2013. Disponível em: https://libertarianismoedarwinismo. wordpress.com/2013/09/14/paradoxo-da-impossibilidade-do-otimo-de-paretoliberal-formulacao-por-amartya-sen-respostas-de-gerald-gaus-e-james-buchanan/, acessado em 15/08/2017. 